\title{
Quando se perde o sentido da vida: valores em textos de suicidas
}

\section{Evandro de Melo Catelão}

Docente da Universidade Tecnológica Federal do Paraná (UTFPR), Brasil. evandrocatelao@gmail.com

Resumo: Cartas e bilhetes suicidas frequentemente aparecem na vida cotidiana ligados a diversos gêneros do discurso, como reportagens, notícias, inquéritos policiais, páginas de redes sociais, entre outros. A argumentação presente nesses documentos já foi e é constantemente explorada no sentido de revelar detalhes sobre motivação, ou sobre a própria vida e morte dos sujeitos que optaram pela morte autoinfligida. Nessa perspectiva e embasado em pressupostos da Retórica e Nova Retórica, este artigo visa apresentar aspectos relativos à argumentação e à noção de "valor" presentes nesses textos. Trata-se de um prolongamento de pesquisa e referencial teórico a respeito da noção de valor na releitura de algumas produções de suicidas coletadas em inquéritos policiais (1896/1940). Pretende-se mostrar ainda como a noção de valor aparece delineada no interior da argumentação do suicida, bem como em estratégias discursivas utilizadas por esses sujeitos no momento da produção dos documentos.

Palavras-chave: Cartas de Suicidas. Discurso Suicida. Argumentação. Valor.

\begin{abstract}
Suicidal notes and letters often appear in our daily lives, mostly linked to different genres of speech, such as news reports, police inquiries, social networking pages, and more. The argumentation in these documents has been and is constantly explored to reveal details about the very life of the subjects who chose self-inflicted death. In this perspective, and based on assumptions of Rhetoric and New Rhetoric, this article aims to present aspects related to the present argumentation and the notion of value in these texts. This is an extension of research and theoretical reference on the notion of value in the analysis of some productions of suicides collected in police inquiries from 1896 to 1940. The aim of this work is to show how the notion of value is highlighted within the suicidal argumentation, as well as in the discursive strategies used by these subjects when these documents were produced.
\end{abstract}

Keywords: Suicidal Notes. Suicidal Speech. Argumentation. Value. 


\section{Introdução}

Em trabalhos anteriores (CATELÃO, 2013), observou-se que a elaboração de uma discussão sobre produções textuais de suicidas implicaria, antes de tudo, entender como se caracterizava a situação sociodiscursiva em que esses autores estavam inseridos. Naquele estudo, concluiu-se tratar-se de uma decisão entre a vida e a morte e, sobretudo, para alguns suicidas, de deixar uma última mensagem escrita, uma última expressão de sua palavra a alguém. Estudos posteriores (CATELÃO e CAVALCANTE, 2017) levaram ao aprofundamento de alguns conceitos teóricos que não eram um foco principal de discussão na primeira empreendida. Este artigo propõe, nesse sentido, um prolongamento teórico no que se refere à noção de valor para o "eu suicida", com base em análise de cartas de suicídio. Objetiva-se, principalmente, apresentar como a noção de valor está delineada no interior da argumentação do suicida, quando se observa sua proposição/forma retórica no plano prototípico da carta.

O encaminhamento teórico será direcionado com base no conceito de valor para a Retórica (REBOUL, 2004) e Nova Retórica (PERELMAN; OLBRECHTS-TYTECA, 1996) presente na discussão dos tipos de acordo (real e preferível). O conceito de valor será ampliado ainda com a discussão realizada por Pedro (2014) que traz outras implicações para o termo. A seleção dos fundamentos foi motivada pela hipótese central do primeiro estudo, isto é, de que o suicida apresentaria uma mensagem final de dominância argumentativa e também com vistas a promover um acordo, convencer ou provocar a adesão do interlocutor.

Como considerações iniciais (as quais serão também mais claramente apresentadas no corpo deste trabalho) a noção de valor, cara à Nova Retórica, mostrou-se principalmente delineada no sentido de expor crenças com o preferível, ou seja, crenças particulares e que remetem também a um acordo com o preferível. Essa conclusão inicial apareceu principalmente quando as crenças e valores observados nos apontamentos de Agrest (2010), nos limites dos valores fundados e infundados, foram confrontados. 


\section{Conceito de valor}

\subsection{Valor em suas bases: Retórica e Nova Retórica}

O termo "valor" é utilizado por diferentes abordagens e linhas teóricas. Na Retórica e Nova Retórica ele aparece na delimitação dos “tipos de acordo" que são estabelecidos no discurso em seu sentido mais geral. Perelman \& Olbrechts-Tyteca (1996, p. 73) afirmam que os acordos servem de premissas ou objetos de crença ou adesão frente ao auditório, movidos pela intenção de persuadir o interlocutor, e são classificados como valores do real e do preferível. Em poucas palavras, os acordos relacionados ao real compreendem os fatos, as verdades e as presunções e seriam orientados a um auditório dito universal'; os acordos do preferível comportam os valores, as hierarquias e os lugares do preferível, sendo direcionados ao que se admite como um auditório particular².

Para a Nova Retórica, os valores são crenças ou convicções dotadas de uma estrutura interna que mobiliza uma ação que evoca outra ação, em geral oposta. A crença na honestidade, por exemplo, implica também reconhecer a desonestidade e com ela uma série de outras crenças existentes na maneira particular do agir humano. Ainda segundo Perelman \& Olbrechts-Tyteca (1996, p. 84-85), recorre-se aos valores "para motivar o ouvinte a fazer certas escolhas em vez de outras e, sobretudo, para justificar estas, de modo que se tornem aceitáveis e aprovadas por outrem". Essas motivações de crenças muitas vezes geram grupos de adesão, ou seja, grupos de pessoas que compartilham um valor.

O campo dos valores apresenta, então, uma pretensão ao universal, contudo varia em relação a um extrato discursivo e outro em razão de aspectos individuais e culturais. Para fins analíticos, nesse contexto, cita-se a subdivisão realizada por Perelman \& Olbrechts-Tyteca (1996, p. 87) em relação

\footnotetext{
${ }^{1} \mathrm{O}$ auditório universal corresponde a um número de participantes que apresentam um perfil semelhante e que, dessa forma, compartilham também determinado ponto de vista facilmente identificável pelo orador, como os indivíduos de uma mesma nacionalidade, toda a humanidade, entre outros (CATELÃO, 2013). "O auditório universal é constituído por cada qual a partir do que sabe de seus semelhantes, de modo a transcender as poucas oposições de que tem consciência" (PERELMAN; OLBRECHTS-TYTECA, 1996, p. 37).

${ }^{2}$ Perelman \& Olbrechts-Tyteca (1996, p.34) definem o auditório particular como qualquer indivíduo ou pequeno grupo de indivíduos cujas atitudes são conhecidas pelo locutor. "O indivíduo que delibera ou o interlocutor do diálogo podem ser percebidos como um auditório particular, cujas reações conhecemos e cujas características somos ao menos capazes de estudar".
} 
aos valores concretos e abstratos no campo da argumentação. Os valores concretos estão ligados a um ente vivo, a um objeto ou um lugar, revelando um caráter único, particular. Os valores abstratos se fixam enquanto princípios da moral ocidental, como lealdade, fidelidade, solidariedade e disciplina atitudes implícitas deflagradas no momento em que há a necessidade de defesa de um valor.

Reboul (2004, p. 165) complementa que falar em valor subentende também reconhecer uma hierarquia de valores ou a supremacia de um valor em relação a outro: acredita-se, por exemplo, ser melhor sacrificar o cão do que o dono. A superioridade sobre um ser ou coisa e as hierarquias entre as pessoas são também manifestações de valores, dividindo-se entre hierarquia concreta, como a superioridade dos homens sobre os animais, e abstrata, como a superioridade da justiça sobre a utilidade.

Uma última instância sobre os valores verifica-se na preocupação com o "lugar", que remete aos valores consagrados e repetidos. Segundo sua origem, o termo "lugar dos valores" possui outras denominações como "lugar-comum" e "tópico". Para Perelman \& Olbrechts-Tyteca (1996, p. 94),

"os lugares designam rubricas nas quais se podem classificar os argumentos", lugares-comuns de argumentos como na classificação de Aristóteles, citados pelos autores, que podem servir a qualquer ciência. "Os lugares-comuns se caracterizam, primitivamente, por sua imensa generalidade, que os tornava utilizáveis em todas as circunstâncias" e que, pouco a pouco, tornou-os comuns, por justificar escolhas num consenso geral sobre o meio de atribuir um valor a algo, como nas proposições que marcam lugares-comuns: "não há nada melhor do que um dia depois do outro", "o bem triunfa sob o mal", "a gente colhe o que planta". Seguem-se ali proposições de argumentos comuns aceitos, mantidos e que são compartilhados de geração em geração pelas pessoas.

\subsection{O ato de valorar e a organização de um regime de valores}

$\mathrm{Na}$ axiologia, ciência do valor ou do ato de valorar (axía: valor do logos no seu sentido etimológico), Pedro (2014, p. 488) apresenta a ideia de valor ligada aos conceitos de moral e ética. Apesar dos laços filosóficos desses dois termos, a exposição da autora liga os valores às premissas de adução de 
valores morais e valores éticos; todavia, nem a moral nem a ética reduzem, obviamente, sua esfera de pensamento e de ação somente a esses tipos de valores, dado que o mundo dos valores é imenso e infinito.

É desse entremeio moral/ética e outros tipos de valores que a autora define valorar como uma ação primordial, própria de nossa existência e da espécie humana. Valoramos tudo à nossa volta, mesmo que se trate de um ato subjetivo e relacional por um lado, mas objetivo e material por outro, "porquanto esse valor advém de um objeto que possui um determinado conjunto de qualidades que não foram indiferentes ao sujeito que as apreciou" (PEDRO, 2014, p. 491). Valorar, então, significa atribuir determinado conjunto de qualidades que não foram ou são indiferentes ao sujeito que as aprecia; o valor é algo notado, ou seja, algo que não passa despercebido à ótica (visão de mundo) de um indivíduo. Essa ótica, em termos analíticos, organiza-se em regimes de valores/crenças representadas segundo o modo de se atribuir um valor. Em sua visão de mundo o sujeito filtra/incorpora, por limites ideológicos e/ou de diferentes modalidades, uma gama de valores: políticos, éticos, morais, estéticos, ecológicos, vitais, espirituais, econômicos e religiosos.

A noção de valorar pode ser complementada com a noção de compartilhamento social de valores. Para a autora, os valores não podem ser considerados entidades autônomas existentes em si, mas sim objetos passíveis de serem apreciados por suas qualidades e por determinado indivíduo ou grupo de indivíduos. Para isso, consideram-se dois pontos: o "bem" que existe por si mesmo e o tipo de valoração feita dele por um sujeito. Aqui se inclui um ponto do "bem" em valoração que pode repercutir argumentativamente: a dependência de um interesse do sujeito no momento de valorar.

Dessas definições, a autora chega ao que chama de particularidades específicas dos valores que seriam também provenientes das intenções e de interesses particulares dos agentes da valoração. Alguns desses valores remetem ao que foi discutido anteriormente como valor para a Retórica e Nova Retórica (o caso da polaridade e da hierarquia de valores) e outros são complementares. A tabela 1 resume o regime de valores apresentados por 
Pedro (2014), aqui relacionados às descrições de Reboul (2014) e Perelman \& Olbrechts-Tyteca (1996) e acrescidos do lugar-comum (ARISTÓTELES, 2011).

Tabela 1

\begin{tabular}{|c|c|}
\hline Características & Descrição do valor \\
\hline Ideais & $\begin{array}{l}\text { Remetem a uma crença ou ao que é digno de importância } \\
\text { a um sujeito. }\end{array}$ \\
\hline Irreais (+ abstratos) & $\begin{array}{l}\text { Não são materiais/palpáveis. Exemplos: lealdade, } \\
\text { solidariedade, disciplina. }\end{array}$ \\
\hline Apreciáveis (+ concretos) & $\begin{array}{l}\text { São passíveis de admiração e de serem estimáveis, como } \\
\text { também inexauríveis - seu valor não se esgota, sendo } \\
\text { também intemporais. }\end{array}$ \\
\hline Obrigatório (+ concreto) & $\begin{array}{l}\text { Não nos são indiferentes e apresentam qualidades } \\
\text { preferenciais. }\end{array}$ \\
\hline Apetecibilidade & $\begin{array}{l}\text { Remete a uma força atrativa sobre o sujeito marcado } \\
\text { como "bom" ou "mau". }\end{array}$ \\
\hline Objetividade (+ concreto) & Intuímos o valor com objetividade. \\
\hline Hierarquia & $\begin{array}{l}\text { Grau de importância ou de preferência que o sujeito } \\
\text { decide atribuir ao bem. }\end{array}$ \\
\hline Heterogeneidade & $\begin{array}{l}\text { Por mais que existam "famílias de valores", há uma } \\
\text { diferença qualitativa entre eles. }\end{array}$ \\
\hline Polaridade ou Bi & $\begin{array}{l}\text { Há valores positivos que correspondem simultaneamente } \\
\text { a valores negativos, como "a guerra se opõe à paz". }\end{array}$ \\
\hline Lugar-comum & $\begin{array}{l}\text { Há valores que já são consagrados e repetidos } \\
\text { historicamente, por exemplo: “o bem triunfa sobre o mal”. }\end{array}$ \\
\hline
\end{tabular}

Fonte: Elaboração do autor com base em Pedro (2014), Reboul (2014) e Perelman \& OlbrechtsTyteca (1996), Aristóteles (2001).

\section{Suicídio: como valoramos a própria vida?}

Ser ou não donos da própria vida é uma questão discutida há muitos séculos pela humanidade e está profundamente ligada ao valor que se dá à vida. É tema frequente e presente na literatura, em situações cotidianas e/ou quando todas as esperanças parecem perdidas. Viver é valorado como dom, dádiva para alguns; para outros, tarefa não muito simples, carregada de confrontos diários e de escolhas que podem desencadear uma série de consequências. $O$ autoquestionamento a respeito do real sentido da vida, ou se realmente a vida faz sentido, é, em suma, tema de diferentes manifestações humanas. 
Creditadas em ações do dia a dia, nossas esperanças no real sentido da vida nos movem e regulam nossas ações: estipulamos metas; aprendemos a lidar com vitórias e fracassos e modelos de comportamento social predefinem o sujeito, que se posiciona frente ao que lhe é imposto diariamente. Olhar para a vida e para a morte envolve tanto atitudes quanto posicionamentos ou pontos de vista recorrentes, compartilhados como singulares, únicos. Algumas materialidades linguísticas são então acionadas a partir do momento em que alguns sujeitos definem o fim de sua vida como o melhor caminho. Deixar ou não deixar algo escrito seria só mera formalidade, mas acaba por registar o mais polêmico dos atos, o ato suicida. Diários, cartas pessoais, letras de música, poemas, entre outros representam uma pequena parte dessas materialidades que em si também representam valores dessas pessoas.

\subsection{Valor e suicídio}

O suicídio se insere na mente das pessoas de muitas formas e, de acordo com o tempo e a sociedade, aciona valores e crenças específicos. De uma prática aceitável, passa de uma conduta necessária (para o eu suicida) a motivo de preocupação ou prática abominada por Deus. De qualquer modo, é notório o desconforto das pessoas e, paradoxalmente, seu interesse pelo suicídio. A prática da morte voluntária, como apresenta Agrest (2010, p. 15), afeta o organismo social e mostra a fragilidade e incapacidade do homem em conhecer suas causas e motivações.

Também fruto de atividades ou ações sociais, o suicídio condensa em alguns discursos um sentido de reprovação, principalmente em culturas ocidentais, marcadas por dogmas cristãos. Nessas culturas, a vida é tida como um dom divino e somente pode ser tirada por uma força também divina. Quanto aos aspectos formadores da visão de suicídio dos sujeitos, Agrest (2010, p. 51) situa os relacionados à economia, ao avanço da ciência e à desmistificação da fé.

Nessa disposição dos fatores, o valor atribuído à vida sofre variação segundo a noção de produtividade (de hoje e do passado). Os avanços tecnológicos, da ciência e da medicina tiraram, segundo a autora, a visão natural da morte, que passou a ser julgada com base na luta contra enfermidades crônicas e terminais (batalha perdida), fazendo com que a vida 
perdesse seu valor, ou que as pessoas perdessem a fé na vida com a inevitável chegada da morte. Para o ato suicida, minimizar a morte significou a incorporação de algumas práticas: a) incorporação do sentido de morrer como um ato sem grandes consequências; b) separação entre vida e morte - a morte que era sagrada, designada por Deus, passa a ser sinônimo de fracasso na sociedade da produção; c) arrogância frente à morte - derrotada pela medicina, a morte é vista como penosa e antiestética para uma sociedade hedonista, bela; d) dessacralização da morte com mudança de valores. Segundo Agrest (2010), na nova sociedade, menos voltada aos valores religiosos, a morte não é mais vontade de Deus; e) negação da morte - a morte simplesmente não existe; f) simplificação da morte e ampliação do sentido de matar/morrer (ato merecido). Nesse sentido, matar ou se suicidar pela crença de se estar fora dos modelos sociais existentes é perfeitamente aceitável ou lei maior.

Em estudos anteriores (CATELÃO, 2013), discutiu-se que, em culturas menos ocidentalizadas, os comportamentos discursivos (motivos, valores, premissas, por exemplo) dos sujeitos suicidas são expressos segundo leis e tabus. O suicídio recebe valor com base no abandono do sentido atribuído à nossa própria existência e é revelado por fundamentos históricos e culturais. Agrest (2010, p. 51) afirma que toda referência ao suicídio entre esses indivíduos reflete atitudes e incômodos sociais inerentes à época e à cultura. No Oriente, por exemplo, a prática da morte voluntária era vista como nobre. No harakiri, a desonra de um guerreiro samurai o condenava à morte em plena subordinação ao amo. Também no Oriente, mais recentemente, a desonra pode se refletir em uma atitude similar em adaptação a um modelo produtivista em que o fracasso profissional não é admitido. Na Oceania, Ásia e África, o suicídio, para os hindus, não se tratava da subordinação do guerreiro ao amo, mas da esposa ao marido pelo suttee, demonstração do amor conjugal e à miserável condição social da esposa após a morte do marido.

Retornando à cultura ocidental, ela está mais arraigada à religião cristã, que liga o sentido de suicídio às práticas condenáveis em que a morte voluntária seria valorada como "ruína a si próprio" e desencadearia uma série de sofrimentos e penalizações em uma outra vida (alma, espiritual). O cristianismo renega a prática suicida, a qual, ao ser propagada no Ocidente, trouxe consigo a doutrina da santidade da vida humana, dádiva divina, bem 
dado por Deus e só tirado por ele. Dentro do dogma cristão, a escolha pela morte voluntária ocasiona tormentos eternos e condenação da alma com base em leis que regulam e castigam a conduta.

Essa mesma valoração levou, historicamente, a outros valores correlacionados. O impedimento ao livre-arbítrio da morte pela lei eclesiástica da Idade Média impedia que o suicida fosse enterrado em solo sagrado, e haveria confisco de seus bens e propriedades caso optasse pela morte voluntária. Posteriormente, parte das leis provenientes de práticas cristãs foram transferidas e/ou ligadas a outras leis capitalistas. No imaginário social essa mudança instituiu um regime de valores de autoexigência cobrada e transmitida aos familiares do suicida, com alguns exemplos representativos do lugar do suicida e de sua família em uma sociedade mercadológica. Na autoexigência, o sujeito que deixa a vida por vontade própria escapa de suas obrigações, ou seja, comporta-se de forma irresponsável com sua nação. No Japão ocidentalizado, o suicida transmitiria sua dívida de trabalho à família, devendo um ente próximo assumir sua função - fato ocasionado em parte pela sucessão de suicídios na construção da ferrovia do Chuo Shinkansen (STROM, s.d. apud AGREST, 2010).

\subsection{Valores fundados e infundados na prática suicida}

O histórico de valores anteriormente descrito gerou parte do que é admitido hoje e do que se acredita ser socialmente aceitável ou não em relação à morte voluntária. O suicídio formou-se como tabu e motivo de preconceito na sociedade contemporânea globalizada. Trata-se, em fim de contas, de um ato, no consenso geral, influenciado por dogmas religiosos, castigável, incompreendido, e que denota parte da incapacidade dos sujeitos em lidar com a morte autoinfligida. Nos poucos casos em que o suicídio assume sentido próximo aos modelos do passado, como meio de resgate da honra, sua acepção alterou-se consideravelmente junto aos ideais modernos, sinalizando uma luta contra os modelos da cultura de massa (CATELÃO, 2013).

No regime de leis, tradições eclesiásticas e provenientes das constituições socioeconômicas pós-Idade Média passaram com o tempo à tradição legislativa do Estado, o que levou mais tarde a não se conceituar o suicídio e a tentativa de suicídio como crime. Esses dados foram compilados 
por Agrest (2010, p. 37), segundo investigações de outros autores e estatísticas que revelaram dois campos distintos de crenças verdadeiras ou falsas em relação ao suicídio. Os registros discursivos de crenças dos sujeitos são divididos pela autora em crenças fundadas e crenças infundadas relativas às causas e motivações do suicídio. As crenças fundadas se apoiam em princípios estatísticos apresentados em diferentes estudos de órgãos governamentais, sendo assim sustentadas como fatos ou verdades em que se assume uma pretensão de validade:

Tabela 2

\begin{tabular}{|l|l|}
\hline Crenças & Registros \\
\hline \multirow{5}{*}{ Fundadas } & $\begin{array}{l}\text { O suicídio ocupa um dos primeiros postos entre as causas } \\
\text { de morte. }\end{array}$ \\
\cline { 2 - 3 } & O suicídio é a manifestação de um transtorno mental. \\
\cline { 2 - 3 } & Pessoas mais velhas se suicidam mais que as jovens. \\
\cline { 2 - 3 } & Os homens se matam mais que as mulheres. \\
\cline { 2 - 3 } & Metade das pessoas já pensou em suicídio. \\
\cline { 2 - 3 } & Há famílias com uma clara tendência ao suicídio. \\
\cline { 2 - 3 } & O suicídio é um ato comum na comunidade gay. \\
\cline { 2 - 3 } & O matrimônio ajuda a preservar a vida. \\
\cline { 2 - 3 } & Os imigrantes se suicidam, as minorias étnicas não. \\
\cline { 2 - 3 } & O trabalho protege contra o suicídio. \\
\cline { 2 - 3 } & O suicídio é contagioso. \\
\hline
\end{tabular}

Fonte: Elaboração do autor com base em Agrest (2010, p. 37)

Por outro lado, as crenças infundadas seriam as não validadas por estatísticas, mas que têm sua manutenção por meio de mitos e tabus que rodeiam o suicídio como uma prática socialmente estigmatizada, ligada sobretudo aos valores dos indivíduos. Apesar de não serem validadas, essas crenças também apresentam proposições que fundamentam a argumentação dos sujeitos que deixam cartas justificando suas mortes voluntárias. 
Tabela 3

\begin{tabular}{|l|l|}
\hline Crenças & Registros \\
\hline \multirow{5}{*}{ Infundadas } & $\begin{array}{l}\text { O suicídio se encontra necessariamente unido ao amor } \\
\text { juvenil (o mito de Romeu e Julieta). }\end{array}$ \\
\cline { 2 - 2 } & $\begin{array}{l}\text { Quem já tentou suicídio uma vez, não tentará } \\
\text { novamente. }\end{array}$ \\
\cline { 2 - 2 } & O suicídio é um hábito de algumas nações. \\
\cline { 2 - 2 } & As pessoas se suicidam à noite. \\
\cline { 2 - 2 } & As pessoas geralmente se suicidam no inverno. \\
\hline
\end{tabular}

Fonte: O autor com base em Agrest (2010, p. 44)

Fundadas ou não, o suicida (nos casos destacados nas análises seguintes), no limite dessas e outras crenças, elabora, como observaremos, um discurso de relativa estabilidade e direcionando seu ato à exclusão social, justificando suas ações e deixando, em alguns casos, de forma documental escrita, seus motivos, valores para a vida e a morte (CATELÃO, 2013).

\section{Valores em cartas de suicidas}

Os documentos representativos de produções suicidas presentes neste artigo fazem parte de uma pesquisa apresentada em 2013 (CATELÃO, 2013). As produções estavam anexas a inquéritos policiais do acervo do Arquivo Nacional do Rio de Janeiro. Tratou-se de uma amostra de inquéritos abertos entre o final do século XIX e início do século XX (mais ou menos durante o período de 1890 a 1940) que aqui aparecem em uma releitura. Nessa seção serão apresentadas cópias digitais de alguns desses documentos nos quais se destacam valores e estética, observados segundo as tabelas 1, 2 e 3 anteriores.

\subsection{Produção 1: sutilezas do amor não correspondido}

O primeiro documento é uma carta de conteúdo suicida produzida em 1909, escrita por uma pensionista, viúva e sem filhos, descrita no inquérito como de "avançada idade". O inquérito expõe ainda que alguns papéis por ela escritos e encontrados sobre um dos móveis de seu quarto de pensão "denunciam a desordem de seu espírito incitado pelos arroubos de uma paixão amorosa mal correspondida”. Destaque para três cartas: duas em um 


\section{tipo de papel comum e uma em faces de papel-seda vermelho dobrado. $\mathrm{Na}$ sequência, um dos documentos na íntegra:}

Carta deixada por Josephina

\section{Rio}

24-8-1909

\section{João}

Quando leres esta, eu já terei te deixado de [ilegível]; é saudade que tens tido de muita constancia! porém o que eu tenho sofrido; é além de tua constancia! a muito que tento matar-me! porem era bastante sorte, para perder tal idéia! o que me fazia sofrer perguntavas! e em ter nos meus ouvidos as tuas palavras, quando havião aquelles, emfernaes ciúmes! odiei, jurei jogar-me! só tu me faria desistir do meu entento! tenho pensado, tenho meditado não acho comcluzão de nada! podendo a tanto tempo fazer-te feliz! tenho me feito uma desgraçada!. por tua cauza! Olha o meu emtento é inabalavel! se eu morrer em um cemitério quero ser levada para a misericórdia! quero ser enterrada!

Como uma verdadeira mendiga! me fizeste a mulher mais desgraçada que pizou [ilegível] criado por Deus: queria ter-te perto de mim nos meus últimos momentos, porem alembrança de que és escravo; me fazia dezistir de tudo! Como em tão pouco tempo passou em minha vida. Tantas durezas! não fosse dizer! sou mesmo uma Idiota como me chamavas! uma nada deixa-me Idiota! Olhe fiz uns pequenos esclarecimentos, não sei o que poderá levar! acazo aonde estão minhas mallas eu muito aprecio as damas desta casa oje emcontrarão quantia possão pegar-lhe a minha de um mês mandeite chamar para fazer-te não donde estava meu dinheiro não oferecertes, emcluo a este vai uma declaração aonde podes procurar. Adeus se feliz com a espoza que te procurava avontade della para poder sair comtigo. Adeus morro Odiando tão vil criatura que ao depois de ser sua foi tão miserável. Adeus para sempre emfiel amante Adeus estes meus últimos horas são para servir como os outros pra fim que dissestes aquelle dia. Adeus João oje eu te perdôo!

Últimos pensamentos

Felicidade

Hé tarde! Meu peito... sugura de dor!

Felicidade! Não pode... mais gozar é tarde

Meus dias são contados e eu sucumba!!

Com minha alma! entristecida por

Tanta dor

Tu queres! Ideal querido! Com tanta [ilegível]!

Tu queres! De mim!.. tão... tarde!

Não vés que minha alma em [ilegível]

[ilegível]

Sem teu amor!

[Continua muitas partes ilegíveis]

Fonte: Arquivo Nacional do Rio de Janeiro 
Além do detalhe estético da escrita em papel-seda do próprio poema que faz parte de um dos documentos, o regime de valores da coleção da suicida remete a uma correlação com o exposto por Agrest (2010) em relação à ideia de suicídio em função do amor não correspondido, direcionado a um tipo de crença não fundada, então ligada à idealização do amor. Além disso, uma correção à crença de que o suicida não seria enterrado em um cemitério "se eu morrer em um cemitério quero ser levada para a misericórdia! quero ser enterrada!” (linha 7). Essa ideia, quando relacionada com a tabela 1, estabelece uma relação com a característica ideal de valor, algo digno de importância para esse grupo de sujeitos, além de mostrar ser um valor apreciável na perspectiva religiosa (uma conduta estimada pelo cristianismo, por exemplo). Remete também ao regime de crenças fundadas (tabela 2) "as pessoas mais velhas se suicidam mais que as jovens". No inquérito a suicida é descrita como uma mulher de avançada idade.

Nas cartas tem-se uma aproximação a uma crença infundada (amor juvenil, tabela 3), em direção ao amor não correspondido, ou idealização do amor que pode, em contraste com outras estruturas do mesmo tipo de proposição, ser creditado como crença fundada, marcando um traço recorrente entre outras cartas de suicidas. O amor não correspondido apareceu com frequência como motivação para o suicídio entre as produções encontradas na pesquisa de Catelão (2013). Esse dado complementa, em certo aspecto, a pesquisa de Agrest (2010), pois os dados da autora não se apoiam nas composições dos autores suicidas, e sim em dados ou estatísticas ligadas mais ao que quantitativamente e cientificamente se tem discutido sobre o assunto.

\subsection{Produção 2: homicídio seguido de suicídio}

O segundo documento dessa categoria foi escrito em 1933 e caracterizase por duas cartas escritas por Horácio G. V., casado, 43 anos de idade, que, segundo ele, mantinha relação extraconjugal com Zélia D. G. (20 anos de idade, solteira - citada na carta). Horácio tentou matar Zélia quando ela atravessava o jardim de sua residência e suicidou-se a seguir. As cartas foram encontradas no bolso do suicida. "No bolso das vestes do morto encontrei uma carta em que Horácio diz ter verdadeira paixão por Zélia e que não 
poderia, jamais, viver sem ela; por isso resolvera mata-la e em seguida, suicidar-se. O comissário do dia: -Savio Magioli" (folha 3 do inquérito original, CATELÃO, 2013, p. 139). As cartas encontradas expõem o descontentamento de Horácio, que, ao ser abandonado por Zélia, decide pelo homicídio da amante seguido de suicídio.

Esteticamente as cartas aparecem dispostas em meia folha de papelalmaço, somando seis faces. A primeira na folha 19 do inquérito datada em “4/12/933" (4 de dezembro de 1933) e a segunda na folha 20 em "29/11/1933" (29 de novembro de 1933), estando, portanto, anexas ao inquérito em ordem decrescente de data de produção. Na sequência, é possível verificar o primeiro documento encontrado na íntegra:

Carta deixada por Horácio

Pagarais a ingratidão com a tua vida

Declaro que faço essa declaração unicamente para que ninguem suponha que eu a mato seje para que ella não se case, ou porque eu queira mas qualquer cousa do que já conquistei.

Por ella cazar-se não é, pois tudo estava combinado que continuaríamos a nos querer bem e ella jurou me que tudo faria para estar commigo em um certo logar.

Para provar que não é difamação de que deshonraria, dou as seguintes provas.

De que existe na parede do lado de fora da privada duas cavidades onde eu pouzava os pés quando subia e só poderia subir com o auxilio d'ella conforme o irmão Pedro viu e deu o alarme chamando o Waldemar que mandando ella abrir a porta me encontrou d'etraz da bacia de banho, e a prova do defloramento o exame pericial attestará assim como poderá affirmar de que não foi um encontro único e obrigado pois tivemos mais de 200 relações.

Nada d'isto eu declararia se não fosse a ingratidão que ella me está fazendo não só de não me fallar como não ligando attenção a nenhum de meus sinaes d'esde o dia 26 de Novembro, e assim tenho lutado para ver se conseguia fallar ainda para resolver como iríamos viver.

Porém com o desprezo completo d'ella resolvi matala d'esde o dia 29, já dei algumas investidas mas faltava-me coragem para matar aquela a quem fui louco e cego de amor, como também pensando a triste situação em que iha deixar minha Maria coitada em que o destino quiz dar uma sorte são infeliz.

Assim ando alucinado cometendo o que minha consciência sempre fugiu, trepando por muros, telhados e janelas para para ver esta ingrata que procura só agora fugir de meus olhares.

Horácio

$4 / 12 / 933$

Fonte: Arquivo Nacional do Rio de Janeiro 
Nessa carta, as intenções do produtor se direcionam à tentativa de expor o ponto de vista de Horácio nas duas situações de produção. No documento é descrita a razão da escrita e do ato; ingratidão é a causa para o homicídio da amante. O homicídio seguido de suicídio é, para seu autor, uma forma de livrar-se da vergonha e dos tormentos causados pela desonra de si e do nome da família, um valor caracterizado como apreciável pelos critérios da tabela 1. Trata-se também de uma crença que, pelo regime exposto por Agrest (2010, p. 44), pode aparecer ligada à autocobrança ou à inquietude com a desonra da família, remetendo a tratar-se de uma preocupação ou conceito social mais arraigado no período de produção dos documentos, isto é, a década de 1930, profundamente marcada por valores patriarcais e existentes até hoje como ideal, apreciável e em relação hierárquica com os valores que fogem a esse ideal (tabela 1).

A carta mostra ainda uma referência à paixão amorosa e ao sentimento de abandono, sendo esses atrelados à desonra, à vergonha e à própria morte como escapismo do que seria uma tortura. É visível nesse discurso o conflito de valores, ideais e hierárquicos (PEDRO, 2014), bem próprios desses textos. $O$ sujeito suicida aparece imerso em diferentes valores conflitantes, mas que de certa forma caracterizam seu estado de espírito.

\subsection{Produção 3: a falta de recursos financeiros}

Esta produção data de 1903 e é a carta de suicídio do Major da Guarda Nacional Joaquim P. L., o qual cometeu suicídio em sua residência com arma de fogo. A motivação é explicitada no texto, numa carta manuscrita em folha de papel tipo almaço, dimensões de $11,5 \mathrm{~cm}$ por $18 \mathrm{~cm}$, pequeno, tipo papelbilhete.

\section{Rio [ilegível] 903}

\section{Declaração}

Há dous anos mais ou menos soffrendo de moléstia incurável, neurasthemia com palpitações no coração a pontos de não poder dormir ultimamente, desanimado e aborrecido da vida a pontos de fugir da sociedade e com receios de enlouquecer, vendo meus interesses soffrer, tenho sido infeliz com alguns negócios de emprego de capital e não tenho corajem de ver meus filhos e mulher soffrer futuramente por falta de recursos em quadro tão calamitoso e não podendo resistir a tal desgraça entendi por termos a minha existência, de 
cujos soffrimentos moraes só Deus é testemunha e por isso me perdoará.

[4]Pesso as almas caridosas piedade $\mathrm{p}^{\mathrm{a}}$. com meus pobres filhinhos.

Nada devo a ninguem.

Joaquim Per. de Lima.

Recomendo a minha mulher que procure meu Irmão Antonio para guial-a.

Meu enterro o mais simples possível para não acarretar despesas inúteis.

Fonte: Arquivo Nacional do Rio de Janeiro

Para Agrest (2010), na sociedade contemporânea, pós-Revolução Industrial, o enraizamento da cultura capitalista proporcionou uma mudança de crenças menos ligadas à religiosidade e mais centradas no consumo e no capital. Essa conduta fez também com que, em alguns casos, o valor dado à vida fosse redirecionado da graça divina para certa crença na artificialidade da vida, guiada por inúmeras autocobranças e preocupações com a imagem, quase sempre associada ao dinheiro ou ao que este pode proporcionar. Com mais evidência no homem do que na mulher, ambos se veem presos à ideia de produzir e consumir em uma escala cada vez maior.

A manutenção desse valor fez e faz com que intuitivamente se acredite que estar fora do ideal capitalista seja motivo de fracasso, vergonha, gerando também sofrimentos e angústias. A carta revela parte desse círculo vicioso que se produz e se reproduz em quase todas as culturas e classes sociais que têm o capitalismo como demarcação econômica, tido como bem ou mal social da autoexigência presumida.

Para o autor do documento, o suicídio é uma saída ao fracasso financeiro (linhas 5 e 6); vergonha e autocobranças são evidentes (linhas 7 e 8). No regime de crenças de Agrest (2010), têm-se articuladas algumas crenças fundadas, por exemplo, a que diz respeito ao sexo do sujeito, masculino, aliada à imagem do homem que tem por obrigação dar "condições" e sustento à família.

O sentido dado à vida, nesse texto, segundo o que discute Agrest (2010), pode estar relacionado ao que a autora classifica como manutenção da imagem pública e à posse de bens. A preocupação com aspectos econômicos prevalece sobre qualquer outra (linha 13). A ideia circula entre ver a família desamparada e a vergonha moral que isso acarretaria, bem semelhante ao tipo de autoexigência apontada na cultura ocidental de que fracasso financeiro seria sinônimo de vergonha. 
O perdão divino é recorrente, e o suicida reconhece a morte autoinfligida como algo condenável, mas, apesar disso, tem a certeza do perdão em razão de acreditar que seu sofrimento é maior e que Deus, no papel de testemunha, perdoará o ato, como em "entendi por termos a minha existência, de cujos soffrimentos moraes só Deus é testemunha e por isso me perdoará." Trata-se ali de espécie de dogma religioso que perpassa quase todas as argumentações de suicidas (CATELÃO, 2013). Na citação anterior, o modalizador "só" carrega uma polifonia que traz a voz do coenunciador, contrário a essa crença, e o exclui, apresentando Deus como o único interlocutor capaz de entender o ato como uma solução, pois só Ele é capaz de visualizar todo o sofrimento vivido, o sacrifício da vida em função da perda do que seria a moral para o eu discursivo.

\subsection{Produção 4: escrita nas bordas do jornal}

Como uma tentativa de suicídio e escrita em $1931^{3}$, a próxima carta destaca-se pelo tipo de suporte utilizado para sua escritura: as bordas da segunda edição do extinto jornal $A$ Noite, de segunda-feira, 7 de dezembro de 1931. O texto apresenta as iniciais $A C R$, autoria do soldado da polícia militar Antonio C. R., que deu dois tiros de garrucha em sua cabeça.

$O$ inquérito cita tratar-se de uma dupla tentativa de suicídio do casal Antonio C. R. e Maria da Conceição [na verdade Maria Elisa B. A., segundo nota de encerramento do auto], sua companheira, que ingeriu substância tóxica. Não há uma ordem precisa dos escritos em razão de serem várias notas nas bordas do jornal, como pode ser observado no anexo a seguir.

Carta de Antônio e Maria da Conceição

Em 8-12-931. Aos caros amigos queiram perdoaime deste gesto. Não é espírito fraco sim é o amor que abriga tudo na vida.

Ao caro amigo José A. Nethe queira perdoai-me. Lembrança a todos.

Antonio

Caro F [ilegível Ferreira]. Queira perdoaime deste meu modo de [ilegível suphotunizar]

$A C R$

\footnotetext{
${ }^{3}$ Neste estudo, apenas essa produção apresenta-se como inquérito policial para tentativa de suicídio. Para outras produções nessa linha e/ou mais detalhes da classificação suicídio/tentativa de suicídio, vide Catelão (2013).
} 
Peço não culpar ninguém, pois os culpados somos nós mesmos. $A C R$

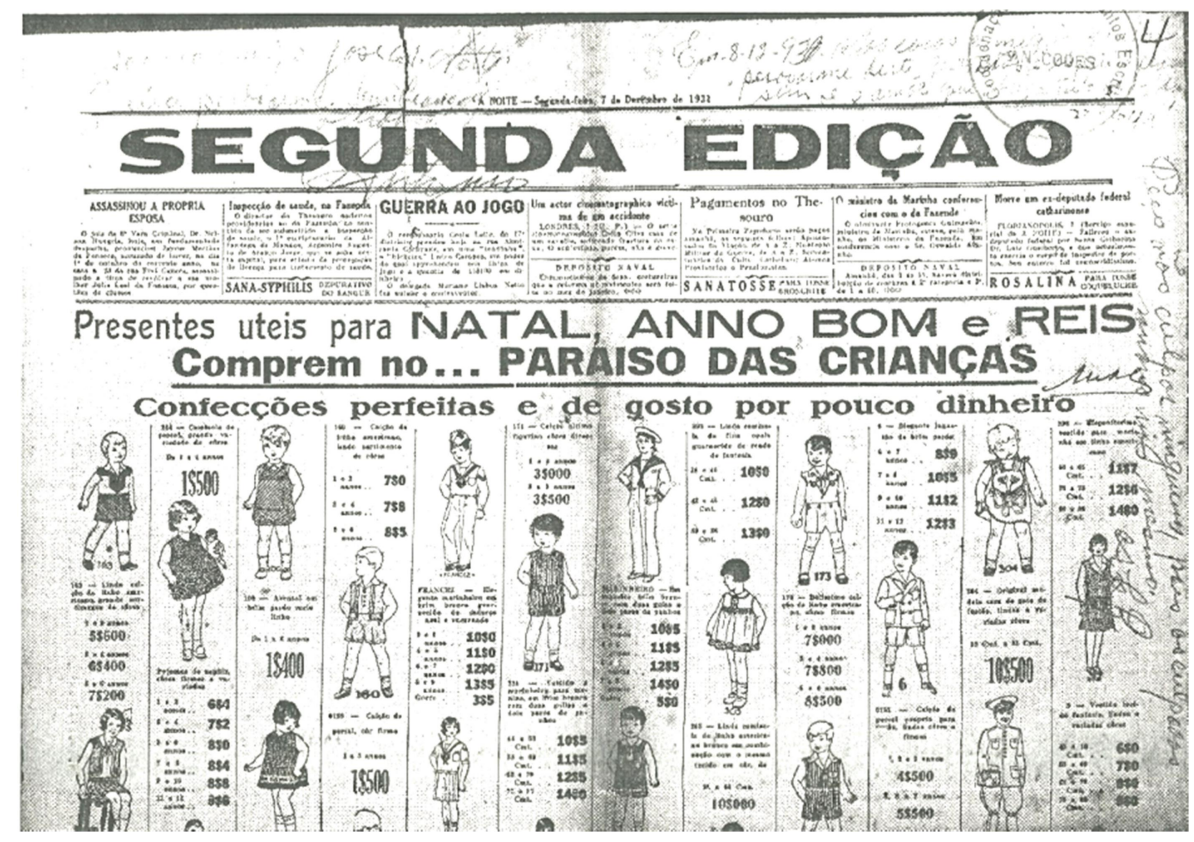

Detalhe do original (fonte: Arquivo Nacional do Rio de Janeiro)

Nesse texto, é possível visualizar em destaque os termos de abertura, como data, corpo da argumentação, seção de despedida e pedidos de perdão, apesar de não haver ou não ser possível estabelecer uma ordem precisa das proposições em função de a escritura ter sido realizada nas bordas da primeira página do jornal A Noite. Seu plano de texto evidencia marcas da carta pessoal, portanto, como já destacado nas análises anteriores, fixas ou convencionais.

A estrutura predominantemente argumentativa é evidente, com destaque para a apresentação da contra-argumentação ou princípio dialógico (retomadas de outras vozes, ADAM, 2011) já no início da carta, antecedido pela data. O valor remetido ao amor impulsiona o ato suicida, mas não há uma apresentação de dados que poderiam contribuir efetivamente ao direcionamento dessa tese, apenas a autoafirmação da culpa é sugerida como dado e a importância que é atribuída ao amor, um valor ideal, mas também irreal no sentido de não ser palpável (pela caracterização do valor criada na tabela 1). A afirmação "não é espírito fraco" mostra um valor frequentemente empregado socialmente de que o suicídio seria um gesto de pessoas não 
"determinadas" ou com transtorno mental (tabela 1 - dados compilados de AGREST, 2010).

O suicídio é justificado pelo amor que seria o sentido para as ações, um amor sugerido como ideal e que suprime todos os outros sentimentos e até mesmo a vontade de viver (hierarquia). O amor romântico, poético, levado ao extremo em que se difunde a ideia do "morrer por amor", ou por "muito amor", diante da imperfeição do mundo. Trata-se nesse e em outros textos analisados neste artigo como "um lugar-comum", valores consagrados e repetidos historicamente (tabela 1 ).

\section{Considerações finais}

Retórica e argumentativamente, a forma epistolar foi o modo encontrado pelos suicidas para traçar sua argumentação e trazer seus valores. A carta caracterizou-se como um gênero de aproximação temporal e espacial do produtor com seu coenunciador, além de também servir, em outro contexto, como prova do suicídio e/ou da tentativa de suicídio nos inquéritos, marcando-se como um gênero com múltiplas funções. Na carta 1 houve, por exemplo, ligação entre os dados firmados por Agrest (2010) e as crenças apresentadas pelos suicidas nos documentos, organizados nas tabelas 1, 2 e 3 . Nesses limites, observou-se representativa ligação do suicídio com o amor não correspondido, não consentido ou não admitido, uma crença que seria não fundada nos limites traçados pela autora (produção 1).

Paralelamente a essa conduta, alguns valores são expressos em preocupações e/ou citações, fugindo do direcionamento de suicídio como uma prática condenável. Entre essas condutas, pedidos como "quero ser enterrada" (produção 1, linha 8), remetem a uma preocupação ou noção de que o suicida não poderia ou não deveria ser enterrado com os mesmos rituais dedicados aos indivíduos cuja morte não foi resultado de uma decisão própria. Ou ainda que ao morto não devesse ser despendido muito dinheiro - "Meu enterro o mais simples possível para não acarretar despesas inúteis" (produção 3, linha 13). Esses dados mostram que os discursos se intercruzam entre valores projetados socialmente (polifonia) e a motivação ou preocupação do suicida em resguardar prestígio, valores cristãos, ou valores 
cultuais ocidentais como preocupação financeira e/ou recomendação dos bens como herança (produções 1 e 3).

Estabelecendo ligação com as imagens de si (ADAM, 2005) apresentadas pelos suicidas e o regime de valores apresentado por Agrest (2010), visualizase um distanciamento principalmente em alguns desses valores marcados pela autora como crença fundada, trazendo uma complementação no que ela discute pela categoria fundado/infundado. Isso implica dizer que os pontos de vista apresentados pelo suicida nas cartas e bilhetes também podem ser usados como categoria para uma análise nesses limites. Relevar-se sensato, ponderado, ciente, foi um comportamento recorrente entre as produções aqui destacadas. Além disso, na produção 3, tem-se uma atenção especial com a autoimagem ligada a uma moral e conservadorismo para o enunciador masculino. Apesar de Agrest (2010) não trazer esse dado nos mesmos termos traçados para este estudo, parece haver uma correlação entre posicionamentos dos suicidas nas cartas e suas crenças.

\section{Referências}

ADAM, Jean-Michel. A linguística textual: introdução à análise textual dos discursos. São Paulo: Cortez, 2011.

- Imagens de si e esquematização do orador: Pétain e De Gaulle em junho de 1940. In: AMOSSY, Ruth. Imagens de si no discurso: a construção do ethos. São Paulo: Contexto, 2005. p. 93-117.

AGREST, Diana Cohen. Por mano propia: estudio sobre las prácticas suicidas. Buenos Aires: Fondo de Cultura Económica, 2010.

ARISTÓTELES. Retórica. São Paulo: Edipro, 2011.

CATELÃO, Evandro de Melo. Revelando motivos: a argumentação de suicidas sob as perspectivas textual/discursiva e retórica. 2013. Tese (Doutorado em Linguística) Setor de Ciências Humanas, Letras e Artes, Universidade Federal do Paraná, Curitiba, 2013.

; CAVALCANTE, Mônica Magalhães. Plano pré-formatado para um gênero. Linguagem em (Dis)curso, Tubarão, v. 17, n. 3, p. 399-417, set./dez. 2017. 


\section{$\mathrm{EI} \square \mathrm{dA}$}

PEDRO, Ana Paula. Ética, moral, axiologia e valores: confusões e ambiguidades em torno de um conceito comum. Kriterion, v. 55, n. 130, p. 483-498, 2014.

PERELMAN, Chaïm; OLBRECHTS-TYTECA, Lucie. Tratado da argumentação: a nova retórica. São Paulo: Martins Fontes, 1996.

REBOUL, Olivier. Introdução à retórica. São Paulo: Martins Fontes, 2004.

Forma de citação sugerida

CATELÃO, Evandro de Melo. Quando se perde o sentido da vida: valores em textos de suicidas. EID\&A - Revista Eletrônica de Estudos Integrados em Discurso e Argumentação, Ilhéus, n. 19, p. 47-67, ago.2019. DOI dx.doi.org/10.17648/eidea-192328. 